\title{
Strengthening the delivery of comprehensive reproductive health services through the community midwifery model in Kenya
}

Wilson Liambila

Population Council

Francis Obare

Population Council

Chi-Chi Undie

Population Council

Harriet Birungi

Population Council

Shiphrah Kuria

See next page for additional authors

Follow this and additional works at: https://knowledgecommons.popcouncil.org/departments_sbsr-rh

Part of the Demography, Population, and Ecology Commons, Family, Life Course, and Society Commons, International Public Health Commons, Maternal and Child Health Commons, and the Women's Health Commons How does access to this work benefit you? Let us know!

\section{Recommended Citation}

Liambila, Wilson, Francis Obare, Chi-Chi Undie, Harriet Birungi, Shiphrah Kuria, Ruth Wayua Muia, and Assumpta Matekwa. 2012. "Strengthening the delivery of comprehensive reproductive health services through the community midwifery model in Kenya," APHIA II OR Project in Kenya Technical Report. Nairobi: Population Council. 


\section{Authors}

Wilson Liambila, Francis Obare, Chi-Chi Undie, Harriet Birungi, Shiphrah Kuria, Ruth Wayua Muia, and Assumpta Matekwa 
TECHNICAL

REPORT

\section{Strengthening the delivery of comprehensive reproductive health services through the community midwifery model in Kenya}
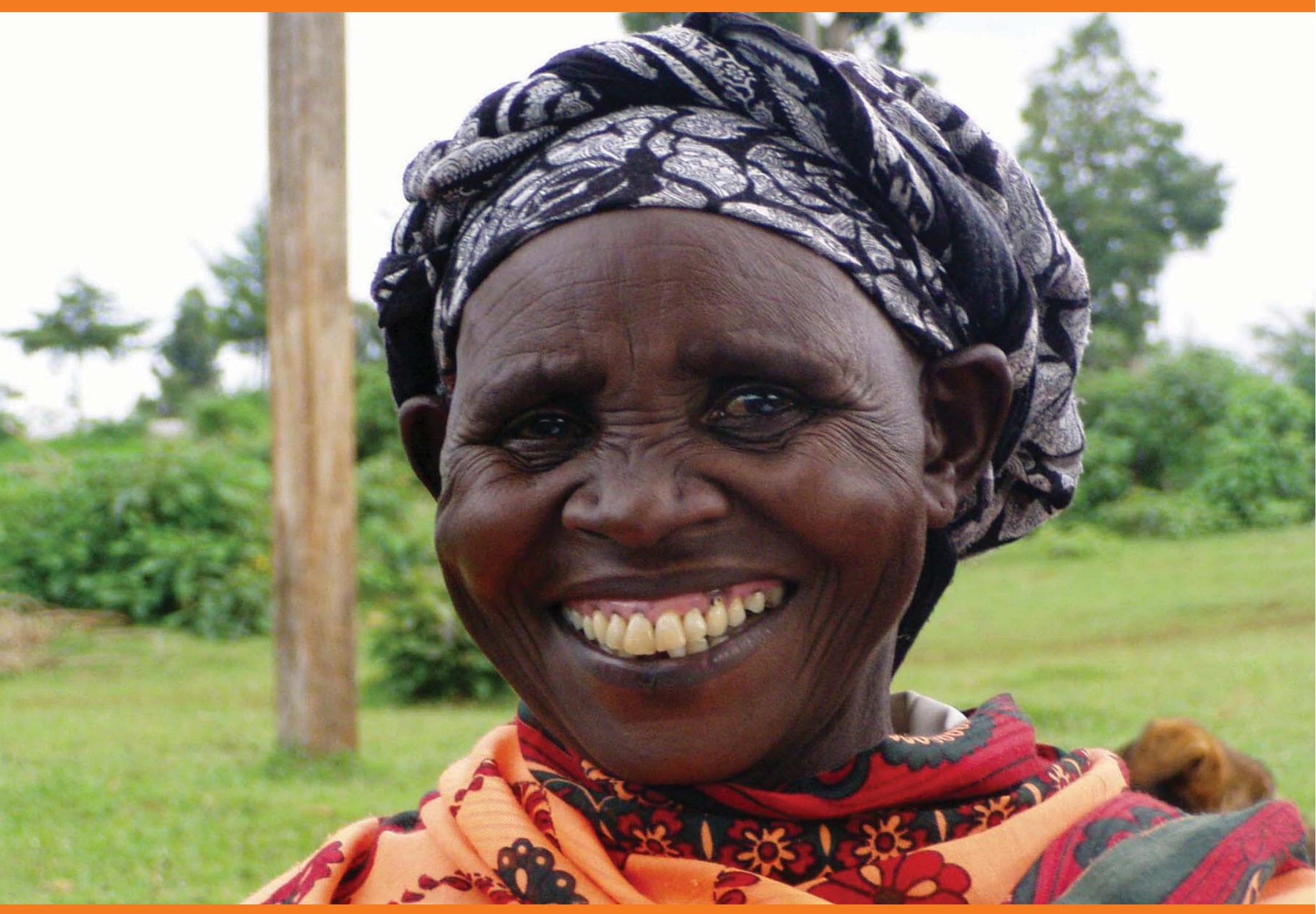

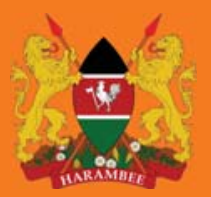

Ministry of Public Health and Sanitation 


\title{
Strengthening the delivery of comprehensive reproductive health services through the community midwifery model in Kenya
}

\author{
APHIA II Operations Research Project/ Population Council \\ Wilson Liambila \\ Francis Obare \\ Chi-Chi Undie \\ Harriet Birungi
}

Ministry of Public Health and Sanitation, Kenya

Shiphrah Njeri Kuria

Ruth Wayua Muia

Assumpta Matekwa

February 2012 
The Population Council, Inc. One Dag Hammarskjold Plaza, New York, New York, 10017.

(C) 2012 The Population Council, Inc.

The Population Council confronts critical health and development issuesfrom stopping the spread of HIV to improving reproductive health and ensuring that young people lead full and productive lives. Through biomedical, social science, and public health research in 50 countries, we work with our partners to deliver solutions that lead to more effective policies, programs, and technologies that improve lives around the world. Established in 1952 and headquartered in New York, the Council is a nongovernmental, nonprofit organization governed by an international board of trustees.

www.popcouncil.org

This publication has been made possible with the generous support of the American people through USAID/Kenya, under the APHIA II Operations Research Project, a cooperative agreement No. 623-A-00-09-00001-00 between the Kenya Mission and the Population Council. The opinions expressed herein are those of the authors and do not necessarily reflect the views of USAID

Cover photo courtesy of the Population Council.

Suggested Citation: Wilson Liambila, Francis Obare, Chi-Chi Undie, Harriet Birungi, Shiphrah Njeri Kuria, Ruth Wayua Muia, Assumpta Matekwa, 2012. Strengthening the Delivery of Comprehensive Reproductive Health Services through the Community Midwifery Model in Kenya. APHIA II OR Project in Kenya. Population Council: Nairobi, Kenya.

Any part of this publication may be photocopied without permission from the publisher provided that copies are distributed without charge and that full source citation is provided. The Population Council would appreciate receiving a copy of any materials in which the text is used. 


\section{Contents}

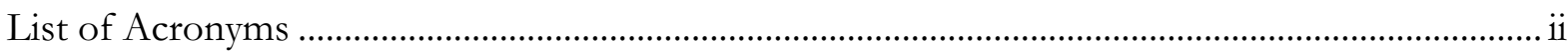

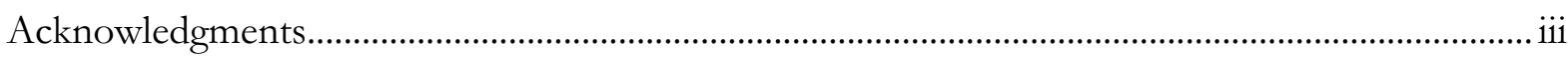

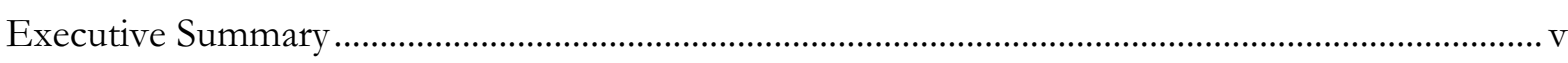

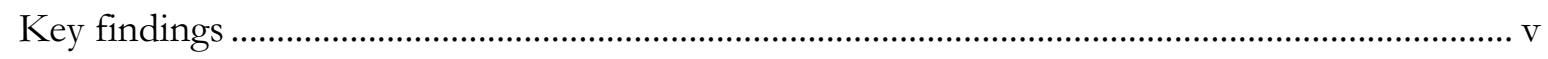

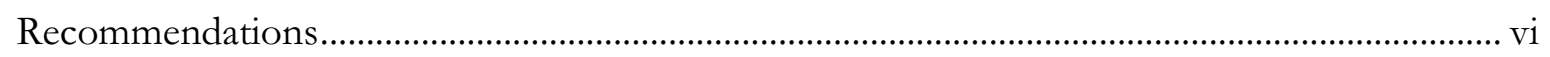

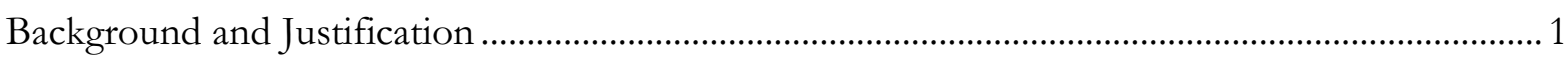

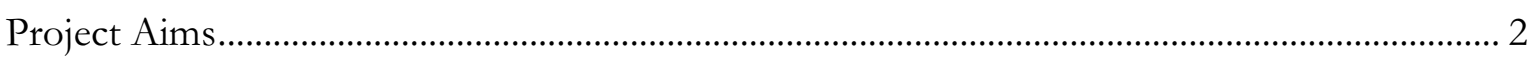

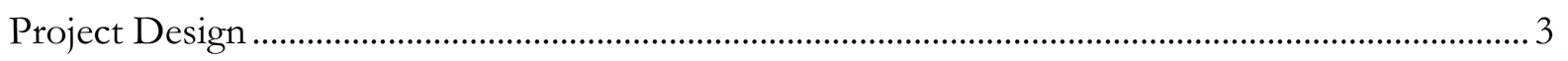

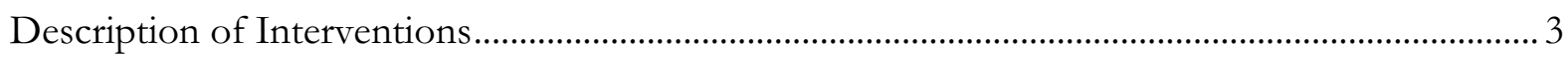

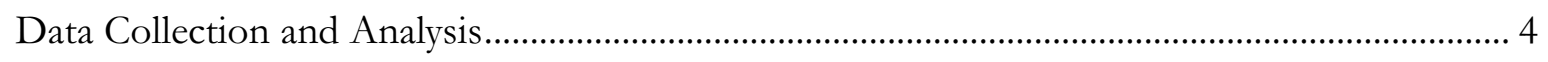

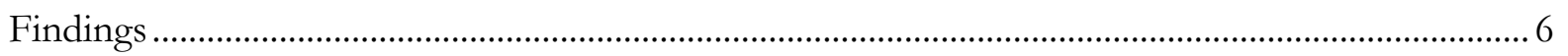

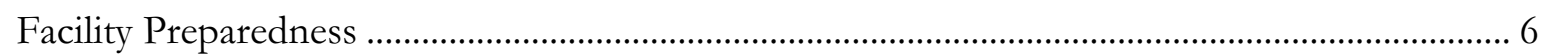

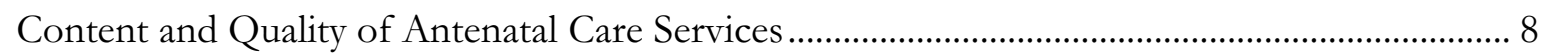

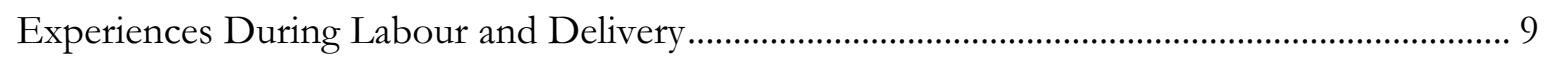

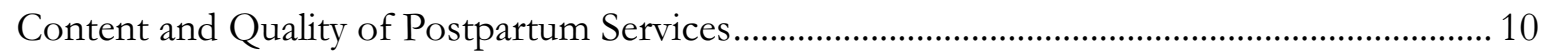

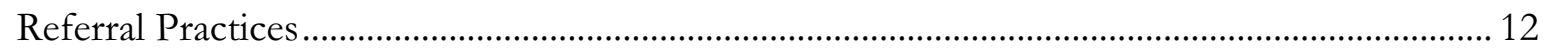

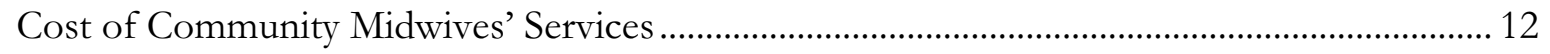

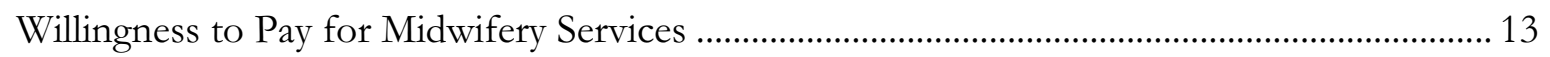

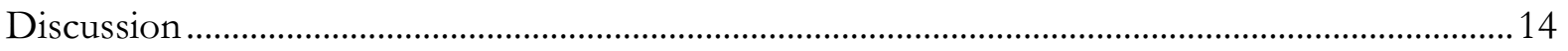

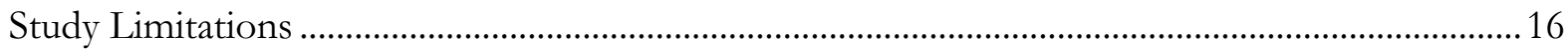

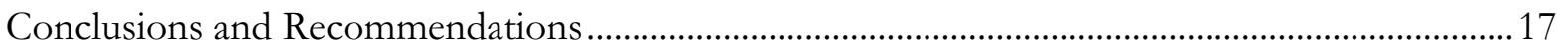

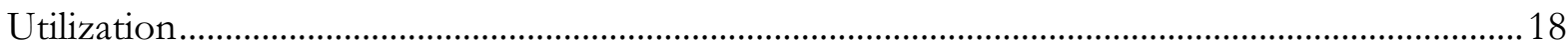

Appendix 1: List of Items for Assessing Facility Preparedness ..................................................... 19 


\section{List of Acronyms}

$\begin{array}{ll}\text { AIDS } & \text { Acquired immune Deficiency Syndrome } \\ \text { ANC } & \text { Antenatal Care } \\ \text { APHIA } & \text { AIDS, Population, and Health Integrated Assistance } \\ \text { ART } & \text { Antiretroviral Drug Therapy } \\ \text { BCS } & \text { Balanced Counselling Strategy } \\ \text { CBD } & \text { Community Based Distributor } \\ \text { CHW } & \text { Community Health Worker } \\ \text { CHEWS } & \text { Community Health Extension workers } \\ \text { CMs } & \text { Community Midwives } \\ \text { DASCO } & \text { District AIDS and STI Coordinator } \\ \text { DHMT } & \text { District Health Management Team } \\ \text { DRH } & \text { Division of Reproductive Health } \\ \text { EOC } & \text { Essential Obstetric Care } \\ \text { ERC } & \text { Ethical Review Committee } \\ \text { FANC } & \text { Focused Antenatal Care } \\ \text { FP } & \text { Family Planning } \\ \text { GOK } & \text { Government of Kenya } \\ \text { HIV } & \text { Human Immunodeficiency Virus } \\ \text { IRB } & \text { Institutional Review Board } \\ \text { IPT } & \text { Intermittent Preventive Treatment } \\ \text { IUCD } & \text { Intra-Uterine contraceptive Device } \\ \text { KDHS } & \text { Kenya Demographic and Health Survey } \\ \text { KEMRI } & \text { Kenya Medical Research Institute } \\ \text { KEMSA } & \text { Kenya Medical Supplies Agency } \\ \text { KEPH } & \text { Kenya Essential Package for Health } \\ \text { LAM } & \text { Lactational Amenorrhea Method } \\ \text { MCH } & \text { Maternal and Child Health } \\ \text { MDGs } & \text { Millennium Development Goals } \\ \text { MMR } & \text { Maternal Mortality Ratio } \\ \text { MNH } & \text { Maternal and Newborn Health } \\ \text { MoH } & \text { Ministry of Health } \\ \text { NASCOP } & \text { National AIDS/STD Control Program } \\ \text { NCST } & \text { National Council for Science and technology } \\ \text { NHSSP } & \text { National Health Sector Strategic Plan } \\ \text { OBA } & \text { Output Based Aid } \\ \text { OR } & \text { Operations Research } \\ \text { PDA } & \text { Personal Digital Assistant } \\ \text { PGH } & \text { Provincial General Hospital } \\ \text { PHMT } & \text { Provincial Health Management Team } \\ \text { PHT } & \text { Public Health Technician } \\ \text { PMTCT } & \text { Prevention of Mother to Child Transmission } \\ \text { PNC } & \text { Post Natal Care } \\ \text { PPC } & \text { Post Partum Care } \\ \text { STI } & \text { Sexually Transmitted Infection } \\ \text { WTP } & \text { Willingness to pay } \\ \text { USG } & \text { United States Government } \\ & \end{array}$




\section{Acknowledgments}

Successful planning, implementation and evaluation of the activities reported in this document were accomplished following important inputs from various institutions and individuals.

The Division of Reproductive Health, Ministry of Public Health \& Sanitation, Kenya, is acknowledged for its leadership in coordinating the implementation of the study on Strengthening the Delivery of Comprehensive Reproductive Health Services at the Community Level in Kenya. In particular, we wish to thank Dr. Bashir Issak - Head, Division of Reproductive Health, Ministry of Public Health and Sanitation for his oversight role in ensuring that the study activities were successfully carried out.

Members of the Provincial Health Management Team (Western Province), District Health Management Teams in Bungoma County (Ms. Jane Makona and Florence Matanda) and the greater Lugari District are acknowledged for having taken part and supported project activities in all phases. In particular, we wish to thank Dr. Quido Ahindukha, the Provincial Director of Public Health and Sanitation, Western Province for playing an oversight role in ensuring that the study activities were successfully carried out. We also wish to thank Annie Mwangi (consultant for the training phase) for ably directing the learning and skills acquisition process and Hellen Magina, FP trainer at the PGH, Kakamega for following up every community midwife after training.

Hospital Management teams and the rural health facility teams of the following facilities: Mabusi Health Centre, Forest Dispensary and Lumakanda District Hospital in Lugari District; and Chwele Sub-District Hospital, Kimilili District Hospital and Tamulega Dispensary in Bungoma district are thanked for facilitating health facility interviews and for linking the study teams to community midwives. We wish to thank Erick Oweya and Mary Mwami Ngendo for data analysis and the data collection team. We wish to acknowledge the inputs from Julius Korir and Nzoya Munguti for the cost analysis and willingness to pay sections of the report.

We would like to thank Ian Askew, Director, Reproductive Health Services and Research, Population Council, Charity Ndwiga and Charlotte Warren for their role in reviewing the study proposal and tools for field work. 


\section{Executive Summary}

Kenya still suffers from the twin problems of high maternal and perinatal morbidity and mortality and a high prevalence of home deliveries under unskilled attendance. In response to these realities, Kenya's strategy for the delivery of community level services emphasizes innovative approaches to address these obstacles. The 'community midwifery approach' was one of the innovations first piloted in Western Province in 2005, in an attempt to address the existing low levels of skilled attendance at birth. A major limitation of the original community midwifery model was that it did not adequately prepare community midwives to offer continuum of care across all the critical phases of maternal health services (antenatal care, essential obstetric care, postnatal and newborn care, including postpartum family planning or FP). Many community midwives (CMs) seem to have limited exposure and knowledge on recent service provision guidelines across these phases. This project therefore sought to strengthen the original model by improving the quality and content of services provided by community midwives.

The overall objective of the project was to strengthen the delivery of FP / reproductive health and HIV (FP/RH/HIV) services at the community level (Level 1). Specifically, the project aimed to: (1) assess the effect of a set of interventions on the operations, content and quality of RH/FP/HIV services offered by CMs from the perspective of clients; and (2) conduct cost analysis and assess client willingness to pay (WTP) for various RH services provided by CMs. This was an operations research (OR) project involving pre- and post-intervention data collection without a comparison group. It was implemented in Bungoma and Lugari districts of Western Province in order to build on the extensive community midwifery work conducted previously in the region. The interventions included revision of existing guidelines and protocols, training of providers, provision of equipment and supplies and creating awareness on the use of community referral cards. The interventions were evaluated through household interviews with previous CM clients. In addition, cost analysis of community midwives' services and willingness to pay (WTP) assessments for various reproductive health services among current and potential users of community midwifery services were also undertaken.

\section{Key findings}

The results showed that the community midwifery model improved clients' access to comprehensive package of RH/HIV including long term family planning methods. Specific findings showed that:

- Most of the health facilities recorded shortage of critical inputs that are key to service delivery such as staff, supplies and reproductive health commodities.

- The proportion of women who sought antenatal care during the last pregnancy the recommended four times modestly improved at the endline from $27 \%$ to $34 \%$.

- Deliveries at the community midwives' homes significantly increased while the proportion of deliveries that occurred at a TBA's house or deliveries by relatives or neighbours significantly reduced at the endline.

- Management of labour and delivery related complications improved at the endline while referrals initiated by community midwives reduced from $22 \%$ at baseline to $7 \%$ at endline mainly due to improved skills of the midwife to deal with complications and services.

- Content and quality of targeted postpartum care services improved. For instance, the proportion of clients who had started using a contraceptive implant after the last delivery significantly increased from 5 to $21 \%$. 
- Cost-analysis showed that the services provided by community midwives are affordable.

However, community midwives do under-charge or under-price their labour costs across all reproductive health services (antenatal care, essential obstetric care, postnatal care and family planning).

- The majority of clients were interested in receiving services although few were willing to pay for the services with price increases.

- Clients are willing to receive a package of reproductive health services from one midwife. More than $90 \%$ of the indicated interest in receiving a package of reproductive health services from a community midwife in future including ANC, delivery, PNC and FP services.

\section{Recommendations}

The study findings suggest the need for:

- Deploying additional staff in health facilities to ensure sustained provision of services and continuation of care for clients referred by community midwives.

- Strengthening the commodities and logistics management system for reproductive health services and supplies that are critical to the provision of emergency care.

- Scaling up community midwifery activities to enable women to seek antenatal care early in pregnancy and establish early contacts during pregnancy with community midwives.

- Strengthening the partnerships between facility midwives and the local facilities where they operate so that CM clients are able to fully benefit from services that are available at the facility level and which cannot be provided by the CMs to ensure continuum of care.

- Encouraging clients seeking ANC about the need to make the recommended four focused visits.

- Undertaking periodic cost-analyses of various RH services to guide pricing and to avoid under-charging or under providing of the services at the community level.

- Conducting information campaigns to promote the services offered by community midwives and to create awareness on the importance of paying for the services to ensure sustainability.

- Revising future curriculum for updating community midwives to reflect the huge demand by current and potential clients for a package of RH services that includes ANC, delivery, PNC and FP services. 


\section{Background and Justification}

Pregnancy and childbirth are still the leading causes of death, disease and disability among women of reproductive age in developing countries. Over 300 million women in the developing world suffer from short-term or long-term illness brought about by pregnancy and childbirth, with 529,000 dying each year. Maternal mortality is highest by far in Africa, where the lifetime risk of maternal death is 1 in 16, compared with 1 in 2800 in the developed world. It is estimated that up to 100,000 maternal deaths could be avoided each year if women used effective contraception ${ }^{1}$.

Maternal mortality in Kenya is at 488/100,000 live births ${ }^{2}$, despite the fact that over $90 \%$ of the causes are preventable. Globally, the major causes of maternal mortality (MMR) are haemorrhage (accounting for 25\%), obstructed labour (accounting for 8\%), sepsis or infections (accounting for $15 \%$ ), high blood pressure/Eclampsia, which accounts for $12 \%$, and unsafe abortion, which contributes to $13 \%$ of maternal deaths. Other direct causes account for $8 \%$ while indirect causes account for $20 \%$ of maternal deaths ${ }^{3}$.

Ninety-two percent of pregnant women make at least one visit of antenatal care (ANC) during pregnancy in Kenya, yet only $47 \%$ of pregnant women attend ANC four times ${ }^{4}$ as recommended by the national guidelines on Focused Antenatal Care (FANC). Furthermore, a study conducted in Western Kenya showed that ANC scheduled visits are made late in the pregnancy period, with no time left for the focused interventions. ${ }^{5}$ Perceived lack of quality of facility-based ANC services by communities was associated with late first ANC visits in the region, denying women a chance for disease detection and the benefits of essential health interventions. Other factors cited were lack of financial resources by women, poor access to transport and mobility.

More than half of pregnant women in Kenya deliver at home under unskilled assistance. ${ }^{6}$ Although the majority $(96 \%)$ of postnatal women visit the health facility for baby immunizations, the family planning needs of women during the postnatal care (PNC) period are often not adequately addressed, leaving many women at risk of unwanted or wrongly timed future pregnancies ${ }^{7}$. In fact, over $60 \%$ of women in the first year after giving birth have an unmet need for family planning. ${ }^{8}$ The rural demonstration units set up in response to primary health care in the 1980s are faced with an inadequate number of health care personnel who are also ill-equipped, leaving the majority of rural women with limited access to family planning, among other reproductive health services. In response to these realities, Kenya's National Health Sector Strategic Plan (NHSSP) II for the period 2005-2010 and the Vision 2030: First Medium Term Plan (2008-2012) emphasize that community level (referred to as "Level 1") health services are to be given priority as a means of reversing the trends in health indicators. The NHSSP II also calls for innovative solutions to address the health needs of Kenyans.

\footnotetext{
${ }^{1}$ World Health Organization. The World Health Report: 2005: make every mother and child count. C World Health Organization 2005, World Health Organization, 20 Avenue, Appia, 1211 Geneva 27, Switzerland

${ }^{2}$ Kenya National Bureau of Statistics (KNBS) and ICF Macro. 2010. Kenya Demographic and Health Survey 2008-09. Calverton, Maryland: KNBS and ICF Macro.

${ }^{3}$ World Health Organization. The World health report: 2005: make every mother and child count. (C) World Health Organization 2005, World Health Organization, 20 Avenue, Appia, 1211 Geneva 27, Switzerland

${ }^{4}$ KDHS 2008/09, ibid.

${ }^{5}$ Anna M van Eijk, et al (2006. Use of antenatal services and delivery care among women in rural Western Kenya: a community based survey. Reproductive Health 2006;

${ }^{6}$ KDHS 2008/09, ibid.

${ }^{7}$ Annie Mwangi and Charlotte Warren, (April 2008). Taking critical services to the home: scaling-up home based maternal and postnatal care, including family planning, through community midwifery: Population Council.

${ }^{8}$ Borda, M. 2006. "Family planning needs during the First Year Postpartum”, Unpublished paper, ACCESS-FP Project, JHPIEGO, Baltimore, USA.
} 
The 'community midwifery approach' was one of the innovations first piloted by the Division of Reproductive Health (DRH) and Population Council in Western Province in 2005, in an attempt to address the existing low levels of skilled attendance at birth in particular. The overall goal of the community midwifery approach was to bring critical maternal health services to the home, via the services of skilled, community-based midwives, thus improving maternal, newborn and infant health. Due to the success of this model, ${ }^{9}$ Kenya's Ministry of Health $(\mathrm{MOH})$ formally commissioned the community midwifery approach in October 2006.

Also, the National Reproductive Health Policy (2006) and the National Road Map For Accelerating the Attainment of the MDGs related to Maternal and Newborn Health in Kenya (final draft 2009) outline the community midwifery model as a key component of saving mothers and their infants.

Community Midwives (CMs) are skilled birth attendants, meeting any of the following criteria:

- A certified health professional with midwifery and family planning (FP) knowledge and skills (nurse midwife, doctor or clinical officer);

- A health professional with obstetric skills and a permanent resident within the community;

- A graduate not yet absorbed into public service, a private practitioner, or retired professional;

- An individual certified by the Nursing Council of Kenya and the DRH, who has attended maternal and neo-natal health $(\mathrm{MNH})$ updates.

The number of women that can now be reached at the household level through community midwives presents an opportunity to strengthen the capacity of the CMs to provide services and expand their mandate by promoting the continuum of care from antenatal care to delivery, postnatal and newborn care. While the original community midwifery model is up and running in many districts, the full package of care recommended by the national guidelines for Focused Antenatal Care, essential obstetric care, postnatal and newborn care, including postpartum family planning especially long-term methods, is currently offered on an ad hoc basis.

Many community midwives have limited exposure and knowledge of recent service provision guidelines for focused antenatal care, prevention of mother-to-child transmission (PMTCT) of HIV, delivery and post-partum care, as well as the provision of a continuum of care. This project therefore aimed to strengthen the original model by improving the quality and content of services provided by community midwives. The project responds to the Ministry of Health's efforts to improve access to reproductive health services at the community level ${ }^{10}$ thereby contributing to the Government of Kenya $(\mathrm{GOK})$ goals of achieving healthier behaviours and increased use of high quality reproductive health $(\mathrm{RH}) / \mathrm{FP}$ services.

\section{Project Aims}

The overall objective of the project was to strengthen the delivery of family planning/ reproductive health and HIV (FP/RH/HIV) services at the community level (Level 1) by improving the quality and content of services provided by CMs. Specifically, the project aimed to:

1. assess the effect of a set of interventions on the operations, content and quality of $\mathrm{RH} / \mathrm{FP} / \mathrm{HIV}$ services offered by CMs from the perspective of clients;

2. conduct a cost analysis and assess client willingness to pay (WTP) for various RH services provided by CMs.

\footnotetext{
${ }^{9}$ Taking critical services to the home: scaling-up home based maternal and postnatal care, including family planning, through community midwifery: Population Council. See for example, Annie Mwangi and Charlotte Warren, (April 2008).

${ }^{10}$ Ministry of Health (2006): Taking the Kenya Essential Package for Health to the Community: A Strategy for the Delivery of level one services, Published by: Health Sector Reform Secretariat Ministry of Health, Afya House.
} 
The hypotheses of the study were as follows:

- Clients are more likely to receive comprehensive ANC and post-natal care services from trained midwives than before.

- Clients with complications during pregnancy are more likely to receive prompt management and referral from CMs than before.

- Clients who receive services from the trained community midwives are more likely to receive a continuum of care during pregnancy, delivery and post-partum period than before.

- The majority of women in the reproductive age group are willing to pay for various reproductive health services provided by community midwives at the community level.

\section{Project Design}

This was an operations research (OR) project involving pre- and post-intervention data collection without a comparison group to assess intervention effects. Four inter-related project phases were involved, namely, pre-intervention data collection phase, intervention development and implementation phase, intervention monitoring phase, and the post-intervention data collection phase. The project was implemented in Bungoma and Lugari districts of Western Province in order to build on extensive community midwifery work conducted previously in this Province.

\section{Description of Interventions}

Intervention development took 2 months (December 2010-January 2011), while implementation of the interventions lasted 6 months (February 2011-July 2011). The interventions were preceded by formative research involving focus group discussions (FGDs) with CMs and in-depth interviews with the Provincial Health Management Team (PHMT), District Health Management Teams (DHMTs), and health facility in-charges. The purpose of the formative research was to obtain the views of the stakeholders on the possible interventions that could improve and sustain the CM model. ${ }^{11}$ The following interventions were implemented:

(i) Revision of existing guidelines and protocols

(ii) Conducting training/updates for providers

(iii) Provision of equipment and supplies

(iv) Creating awareness on use of community referral cards through DHMTs

\section{(i) Revision of existing guidelines and protocols}

The existing guidelines for implementing safe motherhood activities as well as those guiding the implementation and training of community midwifery activities were reviewed and updated to cater for the training of community midwives in expanded roles including the provision of long-term family planning methods. The review entailed identification of gaps in the current training materials and developing new content or adapting the existing guidelines and standards to address the knowledge and skills-gap. For instance, through this process, two new sections, namely the use of Balanced Counselling Strategy- Plus (BCS-plus) and skills on insertion and removal of IUCD and implant were added to the existing training materials for community midwives.

\footnotetext{
${ }^{11}$ Population Council 2011: Strengthening the delivery of comprehensive reproductive health services at the community level in Kenya: Findings of a formative study
} 


\section{(ii) Training/updates of providers}

A total of 38 community midwives were chosen by the DHMTs in Bungoma and Lugari districts to undergo training in key safe-motherhood components namely: focused antenatal care, PMTCT, delivery, and post-partum care guidelines, and in the provision of continuum of care. The training was conducted over a period of 10 days in a busy hospital (onsite) in February 2011. It involved a total of 38 community midwives (21 from Bungoma district and 17 in Lugari) identified by the District Public Health Nurses (DPHN) and the District Reproductive Health Coordinators (DRHC). The training covered the provision of long-term family planning methods, infection prevention, anatomy and physiology of the reproductive system, family planning and HIV integration, skills demonstration, Balanced Counselling Strategy (BCS)-plus, supervision and monitoring, and reporting and linkages with the Ministry of Health facilities. Trainers were drawn from the Provincial Reproductive Health Coordinator's office, Kakamega Provincial General Hospital (PGH), Bungoma and Lugari District Public Health Nurses' offices, and DRH. The community midwives also received updates on business (entrepreneurial) skills. The training was followed by four weeks of supervision in an environment where the CMs operate.

\section{(iii) Provision of equipment and supplies}

The Division of Reproductive Health guidelines stipulate that trained midwives should be provided with a range of essential equipment and supplies by DHMTs. DRH provided a number of basic equipment and supplies to the trained community midwives in February 2011 as part of the intervention activities, including contraceptive commodities (implants and IUCD), blood pressure machines, and weighing scales.

\section{(iv) Creating awareness on the use of community referral cards}

Referral of clients especially those with complications or those whose needs cannot be adequately addressed at the community level is an integral activity of the community midwife's role. To assist community midwives undertake this exercise, they were updated on the use of community referral cards. The cards are filled by community midwives and given to the clients who are being referred or their relatives who in turn hand them over to the receiving facilities. Although the cards had been developed earlier by MOH, the project supported the DPHNs and DRHCs in both districts to create awareness on their use and to distribute the cards to CMs.

\section{Data Collection and Analysis}

Data collection involved health facility assessment, household interviews, assessment of willingness to pay (WTP) for various reproductive health services, and cost analysis.

\section{Health Facility Assessment}

The purpose of health facility assessment was to determine the preparedness of facilities to support the CM model. The assessment was conducted at baseline. Following consultations with DRH, PHMT, and DHMTs, six health facilities were purposively selected for the assessment based on the following criteria:

- Minimum of two providers qualified in and currently providing FP/maternal and newborn $(\mathrm{MNH})$ services;

- Demonstrated evidence of previous support to community midwives for activities such as sharing reports, supplies and equipment.

The facilities selected were: Mabusi Health Centre, Forest Dispensary and Lumakanda District Hospital in Lugari District; and Chwele Sub-District Hospital, Kimilili District Hospital and Tamulega Dispensary in Bungoma District. A structured questionnaire was used to collect information on staffing levels in $\mathrm{MCH} / \mathrm{FP}$, maternity and laboratory units as well as in the whole facility. The questionnaire was administered by trained research assistants with training in clinical 
medicine and nursing to facility in-charges or departmental heads of the respective units. Besides staffing, information was also captured on:

- FP commodities,

- HIV testing reagents,

- general supplies,

- protocols for service delivery and their use in consultation/counselling rooms,

- registers and other data collection tools in consultation/counselling rooms, and

- infrastructure.

\section{Household Interviews}

Household interviews were conducted at both baseline and endline with women aged 15-49 years who had delivered in the past six months before the survey. The baseline interviews took place in September 2010 while endline survey was conducted one year later (September 2011). First, CMs were selected from the DHMT records based on those who were active. The selected CMs then provided a list of women whom they provided ANC, delivery or PNC services in the past six months. From this list, the research assistants selected any six post-partum clients whom they followed to interview using a structured questionnaire. A total of 55 active CMs at baseline and 38 (those who participated in the training) at endline provided the lists from which study participants were identified.

The research assistants who administered the questionnaire were trained on data collection techniques using Personal Digital Assistants (PDAs) and had prior research experience in collecting maternal/reproductive health-related data. They also received training on the goals of the project, data collection techniques, and ethics over a one-week period. A total of 307 and 313 women were interviewed at baseline and endline, respectively. Information was collected on background characteristics of respondents as well as on the use of antenatal care, delivery, postnatal care and family planning services.

\section{Cost data}

Data on costs were collected at baseline only. The purpose was to determine the unit cost of providing various reproductive health services under the community midwifery model both from the perspective of the client and the CM. Information was collected by trained research assistants from a sample of 55 midwives on the type of capital and recurrent inputs used by community midwives; time input in provision of different services, and client volume for the period 2009 and 2010. Specific items included payment per visit/consultation for ANC services, drugs and supplies, equipment, family planning methods, delivery, and post partum care, communication (e.g. telephone expenses), staff, fixed assets, transport for home visits, and service fee. The costing of the inputs was based on the 2008 prices of inputs obtained from source of supplies including the Kenya Medical Supplies Agency (KEMSA) and private chemists. The ingredient approach was used to cost all the resources used to provide reproductive health services by the CM either in his/her home or in the client's home.

\section{Willingness to Pay (WTP) Assessment}

Willingness to pay (WTP) assessment was conducted at baseline only. The purpose was to measure potential demand for reproductive health services provided by midwives at various cost scenarios with a view to assessing the potential impact of price changes on revenues, utilization and client profile. It involved two sets of participants: clients who had prior experience with CM services (referred to as 'previous or experienced clients' in this report and comprise those who participated in the household interviews) and those that did not have experience with community midwifery services (hereafter referred to as 'potential clients'). A total of 305 experienced and 729 potential clients participated in the WTP assessment. The potential clients comprised women aged 15-49 years who 
delivered at home in the past six months but were not assisted by CMs. They were identified from birth notification forms from the Provincial Administration's offices (Assistant Chiefs). The village elders then assisted with tracing the participants.

Data were collected using a simple structured questionnaire that elicited information on hypothetical price ranges. The sequencing of questions and content followed the approach proposed by Foreit and Foreit $(2004)^{12}$. Questions explored current level of payments and whether clients would continue to purchase the service if price were increased by a certain amount (medium increase, high increase, and lower increase). Experienced clients were asked about their attitude towards the services provided by a CM, the highest amounts of money that they were willing to pay for the various services, what they would do if the prices were increased above their willingness to pay price and the other alternatives they would use in case the midwives' prices rose above the price they were willing to pay. Potential clients were first asked whether they were interested in receiving services from community midwives. Only those who answered in the affirmative were then asked the WTP questions similar to experienced clients.

\section{Analysis}

The data were entered in EPIDATA and analyzed using STATA and SPSS. To assess the effect of the interventions on the content and quality of services provided by CMs, Chi-square tests and significance tests of proportions are conducted to determine if the observed differences between baseline and endline indicators are statistically significant. The interventions are considered to have had an impact if there occurred significant improvements in the reproductive health service indicators received from a CM at endline compared to baseline. To assess clients' willingness to pay for CM services, the percentage of respondents who would accept a certain price (say price $x$ ) was calculated by subtracting the percentage whose price is lower than $x$ from 100. The percentages obtained were used to plot maximum WTP graphs.

\section{Ethical Approval}

The project obtained ethical approval from the Population Council's Institutional Review Board (IRB) and Kenya Medical Research Institute (KEMRI) Ethical Review Committee (ERC) while the National Council for Science and Technology (NCST) granted research clearance.

\section{Findings}

\section{Facility Preparedness}

Findings from the health facility assessment showed that most of the facilities had below the minimum number of staff required to effectively deliver the services (Table 1). For example, according to the $\mathrm{MOH}$ guidelines ${ }^{13}$ the number of medical officers recommended for Level 4 facilities are six while the number of clinical officers recommended for Level 3 facilities (health centres) are three. With respect to supplies and commodities, $67 \%$ of the key items were available in the health facilities (Table 1). The detailed list of items from which the scores were computed is provided in Appendix 1.

\footnotetext{
${ }^{12}$ Foreit, Karen G. Fleischman and James R. Foreit (2004): Willingness to Pay Surveys for Setting Prices for Reproductive Health Products and Services - A User's Manual; POLICY Project (The Futures Group International) and FRONTIERS Project of the Population Council.

${ }^{13}$ Republic of Kenya Ministry of Health Norms and Standards for Health Service Delivery Published by: Ministry of Health, Health Sector Reform Secretariat, Afya House PO Box 3469 - City Square Nairobi 00200, Kenya.
} 


\begin{tabular}{|c|c|c|c|c|c|c|c|c|}
\hline Indicators & $\begin{array}{c}\text { Chwele } \\
\text { SDH }\end{array}$ & $\begin{array}{l}\text { Mabusi } \\
\text { H/C }\end{array}$ & $\begin{array}{c}\text { Forest } \\
\text { Dispensary }\end{array}$ & $\begin{array}{l}\text { Lumakanda } \\
\text { DH }\end{array}$ & $\begin{array}{c}\text { Kimilili } \\
\text { DH }\end{array}$ & $\begin{array}{l}\text { Tamulega } \\
\text { Dispensary }\end{array}$ & Total & $\begin{array}{c}\text { Recommen } \\
\text { ded/ } \\
\text { Maximum }\end{array}$ \\
\hline \multicolumn{9}{|l|}{ Key Staff } \\
\hline Medical officers & 1 & 0 & 0 & 1 & 2 & 0 & 4 & 6 for level 4 \\
\hline Clinical officers & 4 & 2 & 0 & 8 & 3 & 0 & 17 & 3 for level 3 \\
\hline $\begin{array}{l}\text { Registered nurses/ } \\
\text { midwives }\end{array}$ & 4 & 4 & 1 & 13 & 2 & 0 & 24 & 3 for level 2 \\
\hline $\begin{array}{l}\text { Enrolled nurses/ } \\
\text { midwives }\end{array}$ & 5 & 5 & 2 & 14 & 5 & 2 & 33 & $\begin{array}{c}14 \text { for level } \\
3\end{array}$ \\
\hline \multicolumn{9}{|l|}{$\begin{array}{l}\text { Supplies/ } \\
\text { Infrastructure }\end{array}$} \\
\hline $\begin{array}{l}\text { Family planning } \\
\text { commodities in } \\
\text { MCH/FP (score on } 7 \\
\text { items) }\end{array}$ & 7 & 7 & 4 & 7 & 5 & 5 & 35 & $42(0.83)^{*}$ \\
\hline $\begin{array}{l}\text { Testing reagents } \\
\text { available in } \mathrm{MCH} / \\
\text { laboratory } \\
\text { (score on } 6 \text { items) }\end{array}$ & 5 & 5 & 0 & 5 & 5 & 0 & 20 & $36(0.55)$ * \\
\hline $\begin{array}{l}\text { General supplies } \\
\text { available in maternity } \\
\text { (score on } 8 \text { items) }\end{array}$ & 4 & 5 & 1 & 5 & 1 & 4 & 20 & $48(0.42)$ * \\
\hline $\begin{array}{l}\text { Protocols in FP clinic } \\
\text { (score on } 8 \text { items) }\end{array}$ & 6 & 5 & 7 & 7 & 4 & 6 & 35 & $48(0.73)$ * \\
\hline $\begin{array}{l}\text { Protocols in ART clinic } \\
\text { (score on } 8 \text { items) }\end{array}$ & 5 & 5 & 0 & 5 & 4 & 0 & 19 & $48(0.39)$ * \\
\hline $\begin{array}{l}\text { Registers and cards } \\
\text { (score on } 6 \text { items) }\end{array}$ & 4 & 5 & 5 & 6 & 4 & 5 & 29 & $36(0.80)$ * \\
\hline $\begin{array}{l}\text { Infrastructure in } \\
\text { MCH/FP/ maternity } \\
\text { (score on } 9 \text { items) }\end{array}$ & 9 & 9 & 7 & 8 & 9 & 9 & 51 & $54(0.94)$ * \\
\hline \multicolumn{7}{|l|}{ Total Scores } & 209 & 312 \\
\hline \multicolumn{7}{|l|}{ Average scores } & 29.9 & 44.6 \\
\hline \multicolumn{7}{|c|}{ Total Score as proportion of maximum score for supplies /infrastructure } & \multicolumn{2}{|c|}{$\begin{array}{c}29.9 / 44.6=0.67 \\
(67 \%)\end{array}$} \\
\hline \multicolumn{9}{|c|}{$\begin{array}{l}\text { Notes: *Row scores (based on the total number of available supplies/commodities and infrastructure computed } \\
\text { versus recommended or expected maximum number) in the sampled facilities; DH: District Hospital; SDH: Sub- } \\
\text { District Hospital; H/C: Health Centre; MCH: Maternal and Child Health; FP: Family Planning; ART: Antiretroviral } \\
\text { Treatment. }\end{array}$} \\
\hline
\end{tabular}

\section{Characteristics of Study Participants}

Participants in the household interviews and WTP assessment were asked to provide information on a number of socio-economic and demographic characteristics such as age, marital status, and occupation. Most respondents were 20-29 years old, married and engaged in farming or agricultural activities (Table 2). Most of the respondents had also completed primary education and were mainly Protestants. In addition, more than half of the participants were from Bungoma District partly because more CMs were identified in the district compared to Lugari. 


\begin{tabular}{|c|c|c|c|}
\hline \multirow[b]{2}{*}{ Characteristics } & \multicolumn{2}{|c|}{$\begin{array}{c}\text { Baseline } \\
(\%)\end{array}$} & \multirow{2}{*}{ 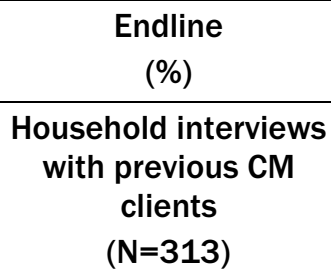 } \\
\hline & $\begin{array}{l}\text { Household interviews } \\
\text { with previous } \mathrm{CM} \\
\text { clients } \\
(\mathrm{N}=307)\end{array}$ & $\begin{array}{l}\text { Household interviews } \\
\text { with potential } \mathrm{CM} \\
\text { clients } \\
(\mathrm{N}=729)\end{array}$ & \\
\hline \multicolumn{4}{|l|}{ District } \\
\hline Bungoma & 57 & 51 & 55 \\
\hline Lugari & 43 & 49 & 45 \\
\hline \multicolumn{4}{|l|}{ Age } \\
\hline$<20$ years & 12 & 15 & 17 \\
\hline $20-29$ & 61 & 55 & 59 \\
\hline $30-39$ & 24 & 27 & 23 \\
\hline 40 and above & 3 & 3 & 1 \\
\hline \multicolumn{4}{|l|}{ Marital status } \\
\hline Unmarried/single & 13 & 13 & 14 \\
\hline Married & 86 & 81 & 85 \\
\hline Divorced/separated & 1 & 2 & 1 \\
\hline Widowed & 0 & 3 & 0 \\
\hline \multicolumn{4}{|l|}{ Occupation } \\
\hline Self-employed & 29 & 12 & 17 \\
\hline Farming/agriculture & 40 & 63 & 57 \\
\hline Skilled labour & 4 & 2 & 4 \\
\hline Unskilled labour & 8 & 14 & 8 \\
\hline Professional e.g. engineer & 5 & 1 & 4 \\
\hline Housewife & 11 & 5 & 5 \\
\hline Student & 3 & 3 & 5 \\
\hline
\end{tabular}

\section{Content and Quality of Antenatal Care Services}

The proportion of clients making the recommended four ANC visits for the most recent birth increased from $27 \%$ at baseline to $34 \%$ at endline although the difference was not statistically significant (Table 3). At the same time, the proportion of clients making five or more visits reduced significantly from $34 \%$ at baseline to $26 \%$ at endline $(\mathrm{p}<0.05)$. This could be attributed to the training of community midwives on focused ante natal care (FANC), during which emphasis was put on the need for ANC clients to attend or make four visits to a community midwife or to a health facility as opposed to unnecessary five or more visits (Table 3).
Table 3: Percent distribution of women by the number and timing of first antenatal care visit for the most recent birth

\begin{tabular}{|l|c|c|c|}
\hline $\begin{array}{l}\text { Number and timing of } \\
\text { ANC visit }\end{array}$ & $\begin{array}{c}\text { Baseline } \\
(\mathbf{N}=307) \%\end{array}$ & $\begin{array}{c}\text { Endline } \\
(\mathbf{N}=313) \%\end{array}$ & -value \\
\hline Number of ANC visits & \multicolumn{3}{|l|}{} \\
\hline None & 1 & 0 & 0.092 \\
\hline 1-3 times & 37 & 41 & 0.337 \\
\hline 4 times & 27 & 34 & 0.075 \\
\hline Five and above & 34 & $26 *$ & 0.040 \\
\hline Timing of first ANC visit & & & \\
\hline 16 weeks and below & 33 & 30 & 0.421 \\
\hline 17-24 weeks & 50 & 48 & 0.618 \\
\hline 25-32 weeks & 17 & 22 & 0.116 \\
\hline 33 weeks and above & 0 & 0 & 1 \\
\hline \multicolumn{4}{|l|}{ Notes: ANC: Antenatal care; *significance at $\mathrm{p}<0.05$} \\
\hline
\end{tabular}


Table 4 summarizes the indicators of quality of ANC services clients received from CMs at baseline and endline including use of individualized birth plan, treated bed nets, and prompt diagnosis and treatment of illness. The proportions of ANC clients who discussed their individual birth plans and PMTCT with the community midwife, set aside money for delivery or for emergencies, and whose complications managed by community midwives improved at the endline were higher at endline than at baseline although the differences were not statistically significant. The proportions that discussed STI/HIV/AIDS in pregnancy as well as counselling and testing for HIV were, however, significantly higher at endline than at baseline (Table 4).

\begin{tabular}{|c|c|c|c|c|}
\hline \multicolumn{2}{|l|}{ Indicators } & $\begin{array}{l}\text { Baseline } \\
(\mathrm{N}=217) \%\end{array}$ & $\begin{array}{l}\text { End line } \\
(\mathrm{N}=179) \%\end{array}$ & p-value \\
\hline \multicolumn{2}{|c|}{$\begin{array}{l}\text { Proportion of clients who discussed their individual birth plans } \\
\text { during ANC with a community midwife }\end{array}$} & 74 & 77 & 0.490 \\
\hline \multicolumn{2}{|c|}{$\begin{array}{l}\text { Proportion of clients who set aside money for delivery / emergency } \\
\text { as part of birth plan }\end{array}$} & 90 & 95 & 0.063 \\
\hline \multicolumn{2}{|c|}{$\begin{array}{l}\text { Proportion of clients who were advised to use treated bed-nets by } \\
\text { community midwife to prevent malaria }\end{array}$} & 81 & 84 & 0.435 \\
\hline \multicolumn{2}{|c|}{$\begin{array}{l}\text { Proportion of clients who discussed the effects of STI/HIV/AIDS in } \\
\text { pregnancy with a community midwife }\end{array}$} & 29 & $37 *$ & 0.034 \\
\hline \multicolumn{2}{|c|}{$\begin{array}{l}\text { Proportion of clients who discussed prevention of mother-to-child } \\
\text { transmission (PMTCT) of HIV with a community midwife }\end{array}$} & 31 & 37 & 0.115 \\
\hline \multicolumn{2}{|c|}{$\begin{array}{l}\text { Proportion of clients who discussed counselling and testing for HIV } \\
\text { and its advantages with a community midwife }\end{array}$} & 31 & $39 *$ & 0.037 \\
\hline \multicolumn{2}{|c|}{ Proportion of clients who developed complications while pregnant } & 21 & 23 & 0.632 \\
\hline \multirow{6}{*}{$\begin{array}{l}\text { Proportion of clients } \\
\text { whose complications } \\
\text { were managed by: }\end{array}$} & & $\mathrm{N}=45$ & $\mathrm{~N}=41$ & p-value \\
\hline & Community midwife & 60 & 66 & 0.565 \\
\hline & Health/Facility & 33 & 34 & 0.921 \\
\hline & Neighbour & 2 & 0 & 0.362 \\
\hline & Relative & 2 & 0 & 0.362 \\
\hline & Self & 2 & 0 & 0.362 \\
\hline
\end{tabular}

\section{Experiences During Labour and Delivery}

The proportion of clients who delivered at the community midwife's home increased from $54 \%$ at baseline to $60 \%$ at endline although the difference was not statistically significant (Table 5). At the same time, the proportions of deliveries that occurred at a TBA's house or that were managed by relatives or neighbours were significantly lower at endline than at baseline. 


\begin{tabular}{|c|c|c|c|c|}
\hline \multicolumn{2}{|l|}{ Indicator } & $\begin{array}{l}\text { Baseline } \\
\text { (\%) }\end{array}$ & $\begin{array}{l}\text { Endline } \\
(\%)\end{array}$ & \multirow[t]{2}{*}{ p-value } \\
\hline \multicolumn{2}{|l|}{ Place of delivery } & $(\mathrm{N}=307)$ & $(N=311)$ & \\
\hline \multicolumn{2}{|l|}{ At community midwife's home } & 54 & 60 & 0.131 \\
\hline \multicolumn{2}{|c|}{ At own house with community midwife } & 16 & 16 & 1.000 \\
\hline \multicolumn{2}{|l|}{ Traditional birth attendant's home } & 2 & 0 * & 0.012 \\
\hline \multicolumn{2}{|c|}{ At own house with traditional birth attendant } & 1 & 0 & 0.077 \\
\hline \multicolumn{2}{|c|}{ Health facility } & 9 & 9 & 1.000 \\
\hline \multicolumn{2}{|l|}{ Community midwife's clinic } & 16 & 15 & 0.731 \\
\hline \multicolumn{2}{|l|}{ Own/relative/ neighbour } & 2 & 0 * & 0.012 \\
\hline \multicolumn{2}{|c|}{$\begin{array}{l}\text { Proportion of clients who experienced complication (s) while } \\
\text { in labour or during delivery }\end{array}$} & 13 & 9 & 0.111 \\
\hline \multirow{3}{*}{$\begin{array}{l}\text { Period during which complications } \\
\text { developed after the onset of labour or } \\
\text { delivery }\end{array}$} & $<30$ minutes & $49(N=41)$ & $44(\mathrm{~N}=27)$ & 0.686 \\
\hline & $>1 / 2$ hour-1hour & $17(\mathrm{~N}=41)$ & $15(N=27)$ & 0.826 \\
\hline & $>1$ hour & $34(N=41)$ & $41(N=27)$ & 0.558 \\
\hline \multirow{2}{*}{$\begin{array}{l}\text { Proportion of clients whose complications } \\
\text { were managed by the community midwife }\end{array}$} & Managed & $78(\mathrm{~N}=41)$ & $93(\mathrm{~N}=27)$ & 0.099 \\
\hline & Referred & $22(N=41)$ & $7(N=27)$ & 0.099 \\
\hline
\end{tabular}

*significance at $\mathrm{p}<0.05$

Clients were further asked whether they experienced any complication (s) while in labour or during delivery, and how soon the complications developed. They were also asked about the role of the community midwife in the management of complications. The proportion of complications that were managed by community midwives increased from $78 \%$ at baseline to $93 \%$ at endline while referrals initiated by community midwives reduced from $22 \%$ at baseline to $7 \%$ at endline (Table 5). However, in both cases, the differences were not statistically significant.

\section{Content and Quality of Postpartum Services}

The proportion of clients who received a check-up in their own home with a community midwife significantly decreased from $42 \%$ at baseline to $25 \%$ at endline (Table 6 ). At the same time the proportion of clients whose check-up took place at the CM's home increased significantly from 33\% at baseline to $50 \%$ at endline. In addition, the proportion of postpartum clients together with their babies who were checked by CMs within 48 hours increased significantly from $52 \%$ at baseline to $67 \%$ at endline. There was also an overall improvement in the quality of postnatal care indicators between baseline and endline with significant improvements in the proportion of clients that started using contraceptive implants since their last delivery. 


\begin{tabular}{|c|c|c|c|}
\hline & $\begin{array}{l}\text { Baseline } \\
\text { (\%) }\end{array}$ & $\begin{array}{c}\text { Endline } \\
(\%)\end{array}$ & p-value \\
\hline Place where the first check up after delivery & $(N=245)$ & $(N=262)$ & \\
\hline Own home with CM & 42 & $25 * *$ & 0.000 \\
\hline CM's home & 33 & $50 * *$ & 0.000 \\
\hline Health facility & 20 & 24 & 0.277 \\
\hline TBAs home & 2 & 0 * & 0.021 \\
\hline Others (specify) & 2 & 1 & 0.351 \\
\hline $\begin{array}{l}\text { Timing for first check-up by community } \\
\text { midwife for mother and baby }\end{array}$ & $(\mathrm{N}=225)$ & $(\mathrm{N}=212)$ & \\
\hline Within 48 hours & 52 & $67 * *$ & 0.001 \\
\hline Between $3-6$ days & 23 & $13 * *$ & 0.006 \\
\hline Between 1 - 2 weeks & 15 & 16 & 0.772 \\
\hline Between 3 - 6 weeks & 8 & 4 & 0.079 \\
\hline More than 6 weeks & 1 & 0 & 0.144 \\
\hline $\begin{array}{l}\text { Proportion of clients who discussed FP } \\
\text { Methods of their choice with a community } \\
\text { midwife }\end{array}$ & 64 & 69 & 0.268 \\
\hline $\begin{array}{l}\text { Proportion of clients who were given } \\
\text { information on how to care for the baby by a } \\
\text { community midwife }\end{array}$ & 77 & 81 & 0.305 \\
\hline $\begin{array}{l}\text { Proportion of clients who were given } \\
\text { information on cord care by a community } \\
\text { midwife }\end{array}$ & 83 & 87 & 0.242 \\
\hline $\begin{array}{l}\text { Proportion of clients who had started using a } \\
\text { implants since their last delivery }\end{array}$ & $\begin{array}{c}5 \\
(N=128)\end{array}$ & $\begin{array}{c}21 * * \\
(\mathrm{~N}=136)\end{array}$ & 0.000 \\
\hline $\begin{array}{l}\text { Proportion of clients who had started using } \\
\text { IUCD since their last delivery }\end{array}$ & 2 & 4 & 0.343 \\
\hline
\end{tabular}

The increase in the proportion of clients using long-acting contraceptives, including implants and IUCDs, is consistent with increased community midwives' workload for family planning methods between baseline and endline (Figure 1). In particular, the number of clients receiving IUCD from CMs more than doubled at endline compared to baseline. Similarly, the number of clients receiving contraceptive implants from CMs increased by more than 20 times at endline than at baseline.
Figure 1: Community midwives' family planning methods workload at baseline and endline

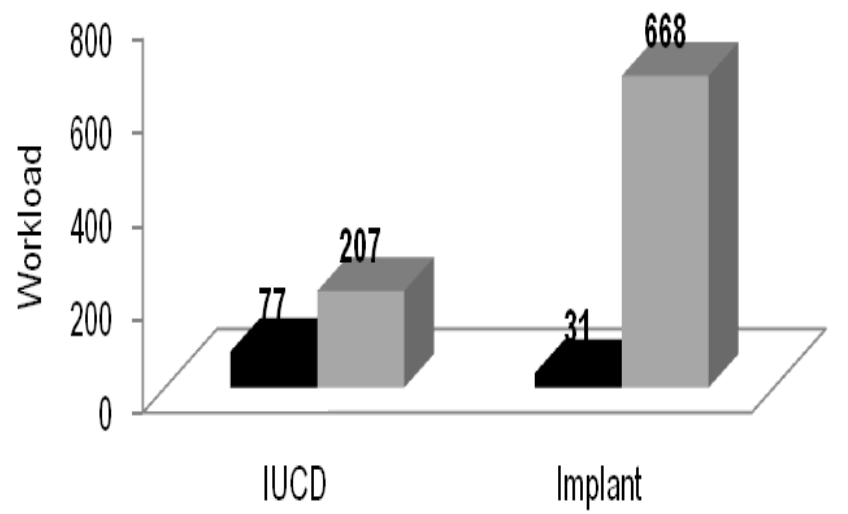

Pre-intervention workload:Aug 2010 -Jan 2011 - Post-intervention workload: Feb 2011-July 2011 


\section{Referral Practices}

Clients were asked whether they had been referred to health facilities for any services by a community midwife during pregnancy and after delivery as well as the type of services they were referred for. The proportion of referrals by community midwives to health facilities reduced from 39\% at baseline to $35 \%$ to endline although the difference was not statistically significant (Table 7). The proportion of clients referred for FP provision significantly reduced from $31 \%$ at baseline to $13 \%$ at endline. The reduction could be attributed to the fact that most midwives were able to provide FP methods to their clients after training.

\begin{tabular}{|l|c|c|c|}
\hline \multicolumn{4}{|l|}{$\begin{array}{l}\text { Table 7: Percent distribution of clients by whether they were } \\
\text { referred for services by a community midwife }\end{array}$} \\
\hline Indicator of referral & $\begin{array}{c}\text { Baseline } \\
(\%)\end{array}$ & $\begin{array}{c}\text { Endline } \\
(\%)\end{array}$ & p-value \\
\hline $\begin{array}{l}\text { Proportion of clients who had } \\
\text { been referred to a health facility } \\
\text { for any services during } \\
\text { pregnancy and after delivery }\end{array}$ & $\begin{array}{c}39 \\
(\mathrm{~N}=306)\end{array}$ & $\begin{array}{c}35 \\
(\mathrm{~N}=311)\end{array}$ & 0.304 \\
\hline $\begin{array}{l}\text { Type of services clients were } \\
\text { referred for }\end{array}$ & $(\mathrm{N}=120)$ & $(\mathrm{N}=108)$ & \\
\hline Family planning provision & 31 & $13^{* *}$ & 0.001 \\
\hline Family planning side effects & 8 & 3 & 0.102 \\
\hline Sputum for Tuberculosis & 2 & 2 & 1.000 \\
\hline $\begin{array}{l}\text { Treatment of medical } \\
\text { conditions }\end{array}$ & 7 & 6 & 0.760 \\
\hline Childbirth complications & 6 & 5 & 0.741 \\
\hline Immunizations for baby & 76 & 80 & 0.467 \\
\hline
\end{tabular}

${ }^{*} \mathrm{p}<0.05 ;{ }^{* *} \mathrm{p}<0.01$

\section{Provision of Continuum of Care}

About one-third of the previous clients received ANC, delivery and PNC services from CMs with no significant difference between baseline and endline $(35 \%$ compared to $33 \% ; p=0.61)$. The proportion of women who received the recommended focused antenatal care (four visits), delivery and targeted postpartum care (three times) from the community midwives was much lower: $2 \%$ at baseline and 1\% at endline $(p=0.75)$.

\section{Cost of Community Midwives' Services}

The unit costs of providing various reproductive health services are presented in Table 8. Overall, the costs per visit are modest across all the services. However, the total costs of delivery and postnatal care services are higher when the client visits the CM than when the CM visits the client. This is largely because of the lower overhead costs incurred when the CM operates outside his/her home or facility.

\begin{tabular}{|l|c|c|c|c|c|}
\hline \multicolumn{7}{|l|}{ Table 8: Unit cost of various services provided by the community midwife (KSh) } \\
\hline Services & Visit 1 & Visit 2 & Visit 3 & Visit 4 & Total \\
\hline Antenatal care & 491 & 343 & 316 & 345 & 1,496 \\
\hline Injectables & 507 & 433 & 427 & 427 & 1,794 \\
\hline Pills & 490 & 403 & 390 & 390 & 1,673 \\
\hline Implants (insertion, follow-up and removal) & 1,781 & 308 & 656 & $\mathrm{n} / \mathrm{a}$ & 2,746 \\
\hline IUCD (insertion, follow-up and removal) & 700 & 420 & 595 & $\mathrm{n} / \mathrm{a}$ & 1,715 \\
\hline Labour and delivery & & & & & \\
\hline CM visits client & $\mathrm{n} / \mathrm{a}$ & $\mathrm{n} / \mathrm{a}$ & $\mathrm{n} / \mathrm{a}$ & $\mathrm{n} / \mathrm{a}$ & 1,421 \\
\hline CM visited by client & $\mathrm{n} / \mathrm{a}$ & $\mathrm{n} / \mathrm{a}$ & $\mathrm{n} / \mathrm{a}$ & $\mathrm{n} / \mathrm{a}$ & 2,208 \\
\hline Postnatal care & & & & & \\
\hline CM visits client & 455 & 292 & 293 & 133 & 1,173 \\
\hline CM visited by client & 632 & 469 & 470 & 311 & 1,882 \\
\hline Notes: IUCD: Intrauterine Contraceptive Device; CM: Community Midwife; KSh: Kenya Shilling \\
\hline
\end{tabular}


A comparison of the labour costs of a Kenya Government nurse with the labour costs of a community midwife shows that the labour costs of a government nurse are much higher than that those of the CM for most of the services except for the removal of IUCDs or implants (Figure 2).

Figure 2: Comparison of labour costs for a government nurse and community midwife (KShs)

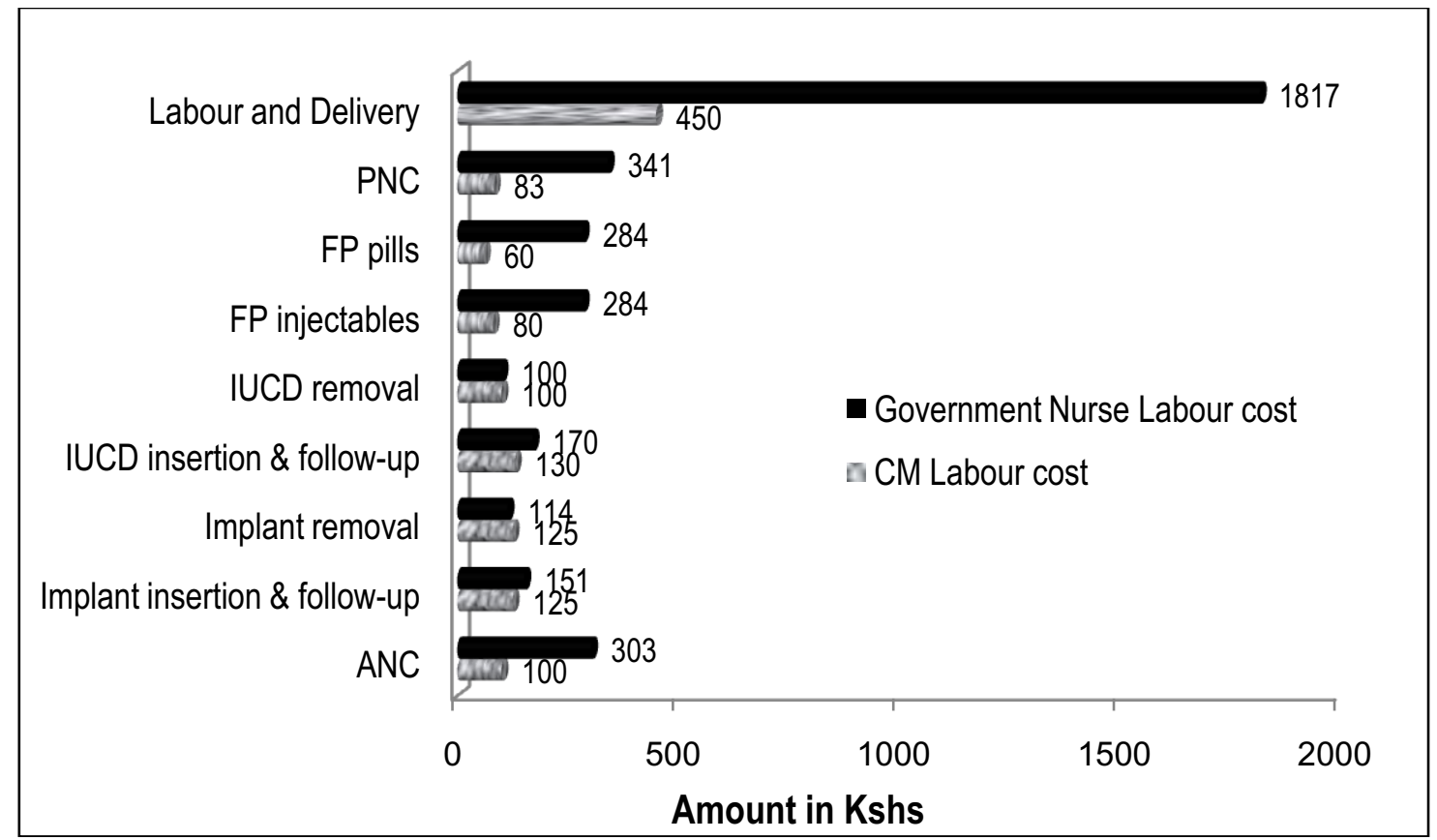

Notes: KShs: Kenya Shilling: PNC: Postnatal Care; FP: Family Planning; IUCD: Intrauterine Contraceptive Device; ANC: Antenatal Care: CM: Community Midwife.

Previous clients were also asked how much they paid for various services provided by CMs. The median amounts paid for various services ranged from KSh. 20 for one postpartum care visit (with a range of 0 to KSh. 3,000) to KSh. 2,000 for continuum of care (ANC, delivery and PNC; range: KSh. 1,500 - KSh. 10,000). The median amounts clients paid for the other services were KSh. 120 for one ANC visit (range: 0 to KSh. 2,500), KSh. 800 for delivery (range: 0 to KSh. 7,000), KSh. 50 for injectables/pills (range: KSh. 20 - KSh. 500), and KSh. 150 for IUCD/implants (range: KSh. 100 KSh. 1,000).

\section{Willingness to Pay for Midwifery Services}

Respondents were asked a series of questions on whether they were interested in receiving CM services and if so, whether they were willing to pay for the services at a medium, higher or lower price increase from the current price. The results are presented in Table 9. Although the majority of respondents were interested in receiving services from $\mathrm{CMs}$, few previous or potential clients were willing to pay for the services at medium, higher or lower price increases. In addition, previous and potential CM clients were willing to pay similar prices for the services. 


\begin{tabular}{|c|c|c|c|c|c|}
\hline \multirow[b]{2}{*}{ Services } & \multicolumn{4}{|c|}{ Percentage interested in receiving $\mathrm{CM}$ services } & \multirow[b]{2}{*}{$\begin{array}{c}\text { Highest } \\
\text { median } \\
\text { price } \\
\text { willing to } \\
\text { pay (KSh) }\end{array}$} \\
\hline & $\begin{array}{l}\text { Respondents } \\
\text { interested in } \\
\text { CM services } \\
\text { (\%) }\end{array}$ & $\begin{array}{c}\text { With } \\
\text { medium price } \\
\text { increase } \\
\%(N)\end{array}$ & $\begin{array}{c}\text { With } \\
\text { higher price } \\
\text { increase } \\
\%(\mathrm{~N})\end{array}$ & $\begin{array}{l}\text { With } \\
\text { lower } \\
\text { price } \\
\%(N)\end{array}$ & \\
\hline Previous clients & $(\mathrm{N}=305)$ & & & & \\
\hline Antenatal care & 84 & $19(48)$ & $48(23)$ & $44(23)$ & 500.00 \\
\hline Delivery & 90 & $15(41)$ & $34(14)$ & $24(56)$ & $1,200.00$ \\
\hline Postnatal care & 75 & $20(45)$ & $29(13)$ & $33(61)$ & 300.00 \\
\hline IUCD/Implant & 76 & $15(35)$ & $26(9)$ & $33(67)$ & 200.00 \\
\hline Injectables/ Pills & 76 & $18(41)$ & $34(14)$ & $40(78)$ & 50.0 \\
\hline ANC, delivery and PNC & 92 & $18(50)$ & $12(6)$ & $27(63)$ & $2,200.00$ \\
\hline Potential clients & $(\mathrm{N}=729)$ & & & & \\
\hline Antenatal care & 88 & $22(139)$ & $35(48)$ & $20(103)$ & 500.00 \\
\hline Delivery & 88 & $8(52)$ & $33(17)$ & $16(95)$ & $1,000.00$ \\
\hline Postnatal care & 79 & $18(106)$ & $39(41)$ & $36(167)$ & 300.00 \\
\hline IUCD/Implant & 82 & $13(77)$ & $29(22)$ & $36(187)$ & 200.00 \\
\hline Injectables/ Pills & 82 & $13(95)$ & $49(47)$ & $30(190)$ & 50.00 \\
\hline ANC, delivery and PNC & 94 & $13(87)$ & $17(15)$ & $22(133)$ & $2,000.00$ \\
\hline
\end{tabular}

\section{Discussion}

The main objectives of this project were to: (1) assess the effect of a set of interventions on the operations, content and quality of RH/FP/HIV services offered by community midwives from the perspectives of clients; and (2) conduct cost analysis and assess client willingness to pay for various RH services provided by CMs. Key findings from the project include:

- Inadequate facility preparedness to support community midwifery model: At the baseline, most of the facilities had below the minimum number of staff required to effectively deliver the services. In addition, only about two-thirds (67\%) of the key items needed to support the community midwifery model were available in the health facilities. Since community midwives are expected to collect these items from the nearby health facilities, a shortage of commodities in the target facilities does not augur well for the community midwifery model. This creates a situation where a shortage of FP commodities in health facilities implies that community midwives also have nothing to dispense to their clients.

- More clients adopted the focused antenatal care approach: The proportion of pregnant women who sought ANC in the last pregnancy four times improved at the endline $34 \%)$ compared to baseline $(27 \%)$ although the difference was not statistically significant. At the same time, the proportion of pregnant women that sought ANC five times and above declined significantly from $34 \%$ at baseline to $26 \%$ at endline. It could be that the women realized that fewer but focused visits are more important than many non-targeted ANC visits. There were also overall improvements in the content of antenatal care received between baseline and endline, for instance, in terms of discussing individual birth plans with the community midwife, setting aside 
money for delivery or for emergencies, receiving advice on the use of treated bed-nets to prevent malaria, and management of complications.

- Deliveries at the community midwife's home increased: The proportion of clients who delivered at the community midwife's home increased from 54\% at baseline to $60 \%$ at endline. At the same time, the proportion of deliveries that occurred at a TBA's house or deliveries by relatives or neighbours reduced significantly at endline compared to baseline. The increase in the proportion of clients who delivered at the community midwife's home could be a reflection of some of the constraints midwives pointed out during the formative interviews including lack or inadequate privacy in some of the clients' homes and poor infrastructure, e.g. lack of water and space.

- Management of labour and delivery-related complications improved: The proportion of complications that were managed by community midwives increased at endline compared to baseline. At the same time, referrals initiated by community midwives reduced from $22 \%$ at baseline to $7 \%$ at endline mainly due to the capacity of the midwife to handle more clients after training than was the case before. It is, however, worth noting that besides skills, handling of complications effectively requires appropriate supplies and equipment as well as basic infrastructure. These issues have to be taken into account while planning to strengthen community midwifery model.

- Content and quality of targeted post partum care services improved: A large proportion of maternal and neonatal deaths occur during the first 48 hours after delivery. Thus, postnatal care is important for both the mother and the child to treat complications arising from delivery, as well as to provide the mother with important information on how to care for herself and her child. The proportion of postpartum clients together with their babies who were checked by CMs within 48 hours increased significantly from $52 \%$ at baseline to $67 \%$ at endline. In addition, the proportion of clients who had started using a long-acting FP method (implant) after the last birth increased significantly from $5 \%$ at baseline to $21 \%$ at endline while the proportion of clients referred for FP provision reduced significantly over the same period (from 31\% to 13\%). These changes suggest that investments in community midwifery model could help in realizing improvements in $\mathrm{MNH}$ indicators that have remained low in the country over the past 20 years.

- There was, however, no significant increase in the proportion of women receiving continuum of care from community midwives: Despite improvements in individual components of reproductive health care services received from CMs, there were no significant changes between baseline and endline in the continuum of care. About one-third of the women received ANC, delivery and PNC services from CMs with no significant difference between baseline and endline (35\% compared to $33 \%$ ). In addition, the proportion of women receiving focused ANC (four visits), delivery and targeted PNC (three times) from CMs was even much lower (2\% at baseline and $1 \%$ at endline). This could be due to the fact that the majority of midwives are limited in the scope of services they can provide. For instance, for focused antenatal care, they may not carry out laboratory tests or offer tetanus injections without the necessary equipment.

- Services provided by community midwives are affordable: The total cost of providing services for each of the RH components ranged from KShs. 1,173 (\$12.75) for postpartum care (for all the four visits when the CM visits the client) to KShs. 2,746 (\$29.85) for implants (insertion, follow-up and removal). In addition, a comparison between the labour costs of a nurse or midwife working in a government facility and a community midwife shows the labour cost of a government nurse are much higher than those of the CMs for most of the services. This implies that community midwives do under-charge or under price their services. Under-charging for services in situations where the provider has no other means of income has several implications. First, it compels the community midwife to make sacrifices including foregoing his/her personal obligations such as purchasing food for herself or family or investing an equivalent amount of 
money into productive ventures whose returns will probably improve her welfare and standard of living. Second, his/her contribution in terms of time could trigger over-expectations on the part of society to demand more of his/her time and resources. Third, under-charging could lead to frustrations and dropout of community midwives from their regular work, hence undermining programme goals.

- Community midwives incur higher costs when they provide services in their premises than when they visit clients' homes: The costs of CM services are much higher when the CMs provide services in their premises than when they visit clients in their homes. This is because operations associated with overheads such as power, cleansing materials, water, gas, use of infrastructure and major equipment do not apply when a CM visits a client outside his/her premise. It is, however, worth noting that majority of the midwives are visited by clients in their homes (about 80\%) especially for ANC, family planning services as well as for labour and delivery. This implies that whereas the transportation costs for community midwives to reach their clients could be low, the overhead costs especially for utilities could be much higher, a factor that should be taken into account while setting up prices for various reproductive health services.

- Although the majority of respondents were interested in receiving services, few were willing to pay for the services with price increases: More than $75 \%$ of current or potential clients were interested in receiving various reproductive health services from community midwives. However, the proportions of clients that were willing to pay for modest increases in the current prices were much lower. In situations where clients were not willing to pay for increased prices, they opted to go elsewhere. When asked about the highest amount of money they were willing to pay to receive CM services, the median amounts ranged from KSh. 50 for injectables/pills (less than US\$1) to KSh. 2,200 (equivalent US\$28) for a continuum of ANC, delivery and PNC services. This suggests that raising prices too high may deny services to poor clients given that substantial proportions of clients were not willing to pay for price increases. However, maintaining low prices (or no payments at all) may make services unsustainable ${ }^{14,15}$.

\section{Study Limitations}

The training phase brought out a number of challenges which future training programmes need to consider. For instance, health facilities which had been selected as training sites were overwhelmed with the number of clients requesting FP services. Some of the health providers working in these facilities did not have adequate skills to provide long-acting FP methods such as contraceptive implants and IUCDs to clients who requested these. This situation was brought about by the leadership in the local communities (especially the members of the health facility committees) who had publicized the training updates for community midwives in the local villages. The inability by the study team to cope with unanticipated turnout of community members who requested FP services, especially long-acting methods, was one of the limitations of the study.

Another challenge had to do with poor adherence to standard procedures. Whereas community midwives (or trainees) were keen to follow prescribed standards for health service provision, some of the health providers stationed in the facilities which were being used as training sites were seen for instance boiling instruments as a method of "sterilization" instead of autoclaving the instruments. Explanations for doing so ranged from not knowing how to use autoclaves to having in place malfunctioning ones. The key point is that there is need to standardize training updates and skills to

${ }^{14}$ UNFPA (2011): Abridged report- on willingness to pay (WTP) survey for modern contraceptives in Nigeria, UNFPA Country Office, Abuja, Nigeria.

15 Karen, G., Fleischman Foreit and James R. Foreit (2004): Willingness to Pay Surveys for Setting Prices for Reproductive Health Products and Services - A User's Manual; POLICY Project (The Futures Group International) and FRONTIERS Project of the Population Council. 
in-service health providers within health facilities to complement the occasional update sessions that community midwives receive so as to avoid potential contradictions and misunderstanding between facility-based providers and community midwives.

The other challenge had to do with the fact that some health providers were not familiar with the use of the Balanced Counselling Strategy (BCS)-plus tools in family planning consultations. This created a situation where nurses in some of the facilities were not using the BCS-plus tools while community midwives were using the tools during FP consultations. Training every health provider on how to use the BCS -plus tools was beyond the scope of the project and was one of the limitations of the study.

\section{Conclusions and Recommendations}

The community midwifery model improved clients' access to a comprehensive package of RH/HIV including long-term family planning methods at the community level. Specifically, clients were more likely to receive comprehensive ANC and post-natal care services including long-term family planning services and prompt management of complications by a trained midwife during and after pregnancy than was previously the case. Nonetheless, although the majority of women in the reproductive age group were interested in receiving services from community midwives, few were willing to pay for the services with price increases. The findings of the study suggest the need for:

- Deploying additional staff in health facilities to ensure sustained provision of services and continuation of care for clients referred by community midwives.

- Strengthening the commodities and logistics management system for reproductive health services and supplies that are critical for the provision of emergency care.

- Scaling up community midwifery activities to enable more women to seek antenatal care early in pregnancy and establish early contacts during pregnancy with community midwives.

- Strengthening the partnerships between facility midwives and the local facilities where they operate so that CM clients are able to fully benefit from services that are available at the facility level and which cannot be provided by the CMs to ensure continuum of care.

- Encouraging clients seeking ANC about the need to make the recommended four focused visits.

- Undertaking periodic cost-analyses of various RH services to guide pricing and to avoid undercharging or under providing of the services at the community level.

- Conducting information campaigns to promote the services offered by community midwives and to create awareness about the importance of payments for the services to ensure sustainability.

- Revising future curriculum for updating community midwives to reflect the huge demand by current and potential clients for a comprehensive package of RH services that includes ANC, delivery, postnatal care and family planning. 


\section{Utilization}

Preliminary findings and lessons learned were communicated locally and regionally in a number of fora:

\section{Local dissemination of results}

In late August 2011, preliminary findings from the study were shared at the technical working group meeting convened by the Division of Reproductive Health (DRH), Ministry of Public Health and Sanitation. The purpose of the meeting was to provide an update on what activities were going on in the field, to share preliminary results and to discuss how to sustain the community midwifery model. Some of the participants present were drawn from the following organizations:

- Population Council

- Nursing Council of Kenya

- National Nurses' Association of Kenya (NNAK)

- Department of Nursing $(\mathrm{MOH})$

- Kenya Obstetrical and Gynaecological Society (KOGS)

- International Federation of Women Lawyers, Kenyan Chapter (FIDA)

The issues discussed included project background, objectives, design, preliminary findings and emerging lessons. The meeting also discussed data from the project monitoring activities that had been forwarded to DRH by the Provincial Reproductive Health Coordinator, Western Province. The participants were informed that the number of contraceptive implants inserted for a period of six months post training (February to July 2011) was almost twenty-one times more than the quantities that were inserted in the six months preceding the intervention (January 2011 to August 2010). During the same period, the consumption of IUCDs increased threefold compared to the pre-intervention period. Participants in the meeting were concerned about the occasional shortage of supplies and FP commodities such as implants and IUCDs. The head of DRH assured the meeting that community midwives should be able to obtain their supplies from the nearest health facilities they are attached to. The need to link community midwifery activities to sustainable pro-poor financing strategies was also discussed at the meeting.

\section{Findings influenced revision of community midwifery guidelines}

The Ministries of Public Health and Sanitation and Medical Services convened a five-day meeting in Mombasa from the $23^{\text {rd }}$ to $28^{\text {th }}$ October 2011 to review the Community Midwifery Implementation Guidelines. Before embarking on the revisions, the two ministries of health had reserved adequate time on the first day of the meeting to share the preliminary findings and to discuss priority issues to be considered in the revision of the guidelines. Participants were drawn from the Nursing Council of Kenya, National Nurses' Association of Kenya (NNAK), Department of Nursing (MOH), Kenya Obstetrical and Gynaecological Society (KOGS), Population Council, JHPIEGO, WHO, Provincial Health Management team (Eastern), and DHMTs of Bungoma, Lugari and Maragwa Districts. Among the items added to the guidelines included the concept of continuum of care (ANC, labour/delivery, postnatal care services including long-term family planning and prompt management or referral of obstetric complications), financing strategies and the need to promote both the public and private sector based models of community midwifery services.

\section{Findings disseminated at the $54^{\text {th }}$ ECSA-HC Ministers' Meeting}

The East, Central and Southern African Health Community - ECSA-HC, hosted the $54^{\text {th }}$ ECSA Health Ministers' Conference in Mombasa, Kenya, 21 - 25 November 2011.The theme of the conference was Consolidating the GainsAddressing High Impact Interventions for Improved Health Outcomes. The conference also served as a forum for Best Practices in Health in the region. The paper 'Using Community Midwives to Improve Skilled Birth Attendance and Promote Continuum of Care in Kenya: Lessons for other ECSA countries' was jointly presented by the Head of the Division of Reproductive Health- Kenya and Population Council staff. Prior to the 54th Ministers' Conference, the Population Council and DRH teams had shared preliminary findings from the baseline findings of the community midwifery project to the ECSA - HC Reproductive Health Experts' meeting, held in Nairobi from 8 - 12 August 2011. In the August meeting, the community midwifery model was viewed as a strategy for accelerating progress towards achieving Millennium Development Goals (MDGs), particularly goal 5b which emphasizes universal access to reproductive health including family planning services by 2015 . Member States were urged to expand maternal, newborn and child health $(\mathrm{MNCH})$ service delivery at the community level and to develop cost effective implementation plans and increase resources devoted to community $\mathrm{MNCH}$. In the $54^{\text {th }}$ Ministers' meeting, community midwives were seen as a key strategy for delivering high-impact interventions at the community level. ECSA countries have similar service delivery obstacles, e.g. shortage of human resources, therefore the community midwifery model could be used to improve access to $\mathrm{FP} /$ maternal and newborn health as well as HIV services in rural areas. The use of community midwives was seen as a good strategy for giving expectant women a chance to seek antenatal care from skilled providers as early as the first trimester thereby creating an opportunity for early detection and management of any complications that may arise. ECSA-HC final resolutions emphasize the need for member states to pay attention to the three delays in labour and delivery, that is, delays in decision making, reaching and receiving care (www.ecsa-hc.org). 


\section{Appendix 1: List of Items for Assessing Facility Preparedness}

Scores were computed for key indicators to assess facility preparedness to support the community midwifery model. Specific items for which scores were computed are outlined below:

- Availability of FP commodities in MCH/FP or maternity unit: 7 items (Combined pill, progestin only pill, injectable, male condom, IUCD, hormonal implants and female condom)

- Testing reagents available in MCH/FP unit, maternity unit or Laboratory: 6 items (Unigold, Determine, and Bioline, reagents for anemia test (Hb/hemocrit/PCV), TB and for pregnancy test).

- General supplies available in MCH/FP, maternity unit or elsewhere: 8 items (Disposable needles and syringes, disposable gloves, specimen bottles for urine, blood specimen bottles, nevirapine tabs/syrup, ciprofloxacin oral, erythromycin oral and cotrimoxazole tabs/syrup.

- Availability of protocols for service delivery in consultation/counselling rooms in FP clinic or ART clinic: 8 items (FP policy guidelines for service providers, guidelines for syndromic management of STIs, PMTCT guidelines, guidelines for Antiretroviral Drug Therapy (ART), Clinical manual for ARV providers, guideline/protocol on HIV testing procedures, pre- and posttest counselling protocol for HIV testing and maternal health guidelines)

- Availability of registers and other data collection tools in consultation/counselling rooms: 6 items (FP register, postnatal register, antenatal register, Family Planning Cards, Pre-ART register, and a referral form for HIV positive clients).

- Availability of infrastructure in FP and ART units in MCH/FP unit or Maternity unit: 9 items (Waiting area is shaded and painted with seats, private space for FP examination, source of clean water in the clinic $24 \mathrm{hrs}$, power to ensure fridge remains functional $24 \mathrm{hrs} /$ day, working autoclave/sterilization, reliable lighting, client toilets, clean water for drinking and clean cups or glasses for drinking water.) 
For more information, contact:

\author{
Project Director \\ APHIA II OR Project in Kenya \\ Population Council \\ General Accident Insurance House \\ Ralph Bunche Road \\ P.O. Box 1764300500 \\ Nairobi, Kenya
}

Tel: 254202713480 - 3

Fax: 254202713479

www.popcouncil.org/projects/239_APHIAll.asp

(P Population Council 